\title{
RESPONSIBLE MANAGEMENT OF DIGITAL DIVIDES: An Oxymoronic Endeavor?
}

\author{
Bernd Carsten Stahl \\ De Montfort University \\ Leicester, U.K.
}

\begin{abstract}
This paper critiques the notion of responsible management of information systems by pointing out the intrinsic contradiction inherent in the idea of managing morality and ethics in information systems. The paper, being part of the tradition of critical research in IS, uses the example of managing digital divides to argue that a traditional view of management (here called heroic management) leads to conceptual problems. It will develop two basic arguments that undermine the possibility of responsible heroic management of digital divides: (1) Normative issues related to digital divides cannot be managed because management is part of the construction of the problem and therefore lacks the detached and objective viewpoint required for rational management. (2) The very concept of responsibility, if taken seriously and applied responsibly (here called reflective responsibility) requires a participative approach that contradicts the traditional top-down approach of heroic management. The paper will conclude with a discussion of what form management of IS needs to take if it wants to be responsible.
\end{abstract}

Keywords Digital divides, responsibility, heroic management, critical research in information systems, ethics, morality, law

\section{INTRODUCTION}

Digital divides are one of the central problems created by information and communication technology. There is a range of literature on digital divides but there is no agreement on what constitutes them, why they are problematic, and how they should be addressed. I will briefly outline some of the problems of digital divides and argue that they are first and foremost ethical issues. If digital divides are ethically problematic, then conventional wisdom in information systems would suggest that they need

Please use the following format when citing this chapter:

Stahl, B.C., 2006, in IFIP International Federation for Information Processing, Volume 208, Social Inclusion: Societal and Organizational Implications for Information Systems, eds. Trauth, E., Howcroft, D., Butler, T., Fitzgerald, B., DeGross, J., (Boston: Springer), pp. 231-243. 
to be managed right in order to solve the problem. The main argument of this paper is that such a conventional understanding of IS as something that can be managed in a rational traditional top-down manner (here called heroic management) is flawed. This becomes particularly obvious in the case of ethically charged issues such as digital divides. Using a critical approach, I will argue that the idea of heroically managing ethical issues in IS is intrinsically flawed and self-contradictory because (1) management produces some of the problems it sets out to solve and (2) the nature of responsible management precludes an heroic approach.

In order to develop this argument, I will first discuss the concept of digital divides and why they are problematic. In a second step, I will question the concept of management and develop my critique of heroic management based on the idea of responsibility. In the conclusion, I will discuss the consequences this will have for managing ethical issues.

\section{MANAGING DIGITAL DIVIDES}

Digital divides are multifaceted issues. They are often discussed in terms of politics and power (Norris 2001). However, the reason why we seem to believe that political solutions must be found is that digital divides are closely linked to social divides and create social injustices (UNDP 1998). There is an enormous amount of inequality in the world (Castells 1997; Schiller 1999) and there seems to be an implicit agreement among many scholars with an interest in divides that this constitutes a moral problem. In this paper I take the view that this perception of moral relevance is at the bottom of attention to digital divides. This does not rule out other approaches but it will provide the necessary link to the concept of responsibility developed later. The section will give a brief introduction to the concept of digital divides and then discuss how a traditional view of management can be applied to digital divides.

\subsection{Digital Divides}

The idea of the digital divides needs to be seen in the context of social justice and is related to a number of phenomena. For this reason I use the plural rather than the possibly more widely used singular of digital divide (see Rookby 2006). Like most concepts, digital divides is hard to define and can be ambiguous (Walsham 2003). The essence of the term is that it reflects a concern that the use of ICT can have an influence on divides and the resulting chances to live a fulfilled and autonomous life. Digital divides are often described in the context of economic development. They can refer to differences between as well as within countries (Kvasny 2002; Kvasny and Keil 2002).

The concept of a digital divide has been discussed since approximately the mid 1990s. In a narrow sense, it refers to "significant demographic gaps in computer and Internet access and usage" (Hacker and Mason 2003, p. 99). During the last decade there has been a large amount of research that tried to establish the reality and relevance of the digital divide. In the United States, for example, the National Telecommunications and Information Administration has collected a large amount of data for a variety of reports, some of which share the title "Falling Through the Net" (see www.ntia.doc. gov). Such a collection of statistics has been criticized as being one-dimensional and 
ideologically motivated (Hacker and Mason 2003). The approach also structures the possible problem by positing that different levels of access are a problem and by concentrating on the lack of access. This by necessity neglects some aspects such as the possible formation of digital elites (see McSorley 2003). It has furthermore been remarked that there are considerable methodological problems when measuring digital divides. Some authors doubt whether the concentration on the digital divide that we find in some streams of research is actually helpful or whether we should not look at more fundamental issues such as the structure and design of the Internet (Couldry 2003).

One can thus state that there is no clear definition of digital divides. It is unclear how they can be described and why they constitute a problem. Digital divides and social divides are, therefore, often closely related and can be seen as expressions of the same problem (Moss 2002; Parayil 2005).

\subsection{Digital Divides in Organizations}

The literature on digital divides concentrates on divides between countries or socioeconomic groups within countries. It rarely touches on issues within organizations. Where it does, it concentrates on digital divides between organizations (Dewan and Riggins 2005). However, there seems to be no profound reason why individual digital divides within organizations are underrepresented. If digital divides are problematic because they affect power, abilities to participate and flourish, then it is easy to see that they apply to organizations as well. There are companies where parts of the workforce have access to ICT and others do not, which corresponds to power differentials. There is some overlap with hourly paid and salaried workers and thus with a more traditional distinction between knowledge and manual workers and socioeconomic classes. However, ICT is moving into more and more areas of work, including those that used to be manual. But even then, there is a difference between those who can and are allowed to use the technology and those who can but may not. Issues of inclusion and well-being that form the moral basis of discussions of digital divides are thus pertinent within organizations as well as within nation states.

These considerations do not seem to be developed in the literature. They also go beyond the confines of this paper. It would be interesting to consider how the literature on digital divides and the literature on organizational use of ICTs might be linked. One relevant aspect would be the question of participation, which is often discussed in conjunction with e-democracy. If such thoughts were extended to commercial organizations, they might have revolutionary implications regarding the distribution of power and resources. At the moment, however, there seems to be nothing more than recommendations for researchers to "examine the extent and impact of the digital divide on the individual worker, the workplace and employers." (Dewan and Riggins 2005, p. 314).

\subsection{Problems and Management of Digital Divides}

Digital divides produce a number of problems that I cannot discuss in depth here. They concentrate our attention on technology, where social issues should be considered. They can appear to reveal problems of justice where differences in access are chosen 
voluntarily. They can even be expressions of Western cultural imperialism that promotes a particular view of the problem and thereby of the possible solution. Despite these problems, it seems reasonable to assume that digital divides are relevant ethical problems that may react to moral intervention (see Kvasny and Truex 2000).

If digital divides are ethically problematic, then one needs to ask how they can be addressed. The traditional answer to this would be to have them managed in a responsible way, so that the problems are overcome. The majority of digital divide issues discussed above relate to the national or international level. "Managers" in charge of such issues will therefore often be politicians, national or international bureaucrats, or representatives of multinational organizations. However, digital divides issues can just as well appear on the organizational level. The responsible manager would then be a normal company manager. A responsible approach to managing ethical issues in the traditional view would be to determine the problem, find a solution, and then implement it. The main argument in this paper is that such a traditional approach is self-defeating because there are intrinsic and conceptual contradictions between the ideas of management and responsibility.

\section{RESPONSIBLE MANAGEMENT OF DIGITAL DIVIDES}

In this section I will briefly discuss the critical approach used in the current paper. I will then introduce the term heroic management as a description of the traditional view of management. This will lead to a discussion why heroic management is a problematic approach to ethical issues in ICT.

\subsection{The Critical Approach to Management}

This paper follows the critical research paradigm. This means, first of all, that it follows a critical intention not only to describe reality, but to change it, which is typical of critical research (Alvesson and Deetz 2000; Cecez-Kecmanovic 2001; Ngwenyama and Lee 1997). The main way in which the critical intention is usually realized is by promoting emancipation (Alvesson and Willmott 1992; Hirschheim and Klein 1994 Klein and Myers 1999; McAulay et al. 2002; Ngwenyama and Lee 1997; Varey et al. 2002). A fundamental problem is how research can emancipate. In this case the answer is that the exposure of a conceptual contradiction in the idea of managing digital divides will open up discursive closures. By demonstrating that a traditional approach to digital divides is incapable of addressing the problem, individuals will be freed from reliance on the problematic approach. This refers to people facing digital divide issues but also managers who may be in a situation where they are ascribed responsibility which they cannot discharge. The importance of language is a central feature of critical research, despite the lack of a recognized methodology (see McGrath 2005). This paper will follow that tradition by attempting to promote emancipation by exposing conceptual contradictions. 


\subsection{Heroic Management}

Etymologically, the verb "to manage" (originally probably derived from the Latin mamus, the hand) comes from the Italian maneggiare to handle, to be able to use skillfully, and originally referred to the handling of horses. Today it means "to conduct, carry on, supervise, or control." While management thus has a wide meaning compatible with different styles of solving problems, it often aims to convey a more specific meaning, which might be termed heroic management (Gosling and Minzberg 2003). My use of this term has been inspired by the idea of postheoric management (Baecker 1994) and the recognition that actual management practices still have a long way to go before they become "post" heroic.

Heroic management stands for the type of management typically taught in many business schools and propagated by management magazines. It depicts the manager as the individual who is personally responsible for success or failure of organizational activities. This orthodox or business school view of management is supported by a relatively standardized and coherent body of knowledge comparable to that of other academic disciplines such as law or medicine (Knights and Willmott 1999). Management takes place in most levels of organizations but the main interest lies in top level management where the strategy of companies is decided (Bourlakis and Bourlakis 2003). Indeed, conventional management wisdom suggests that every organization must have a strategy and that it will be lost in the turbulent environment if it does not have one (Knights and Morgan 1991). Managers are in charge of creating the strategy and aligning organizational efforts with it. A considerable amount of effort is therefore spent describing the qualities and characteristics of the manager. The manager is a role model for employees (and for students of management). He (and he is rarely a she) is "seen as someone who represents what society believes in and whose behavior is regarded to be, in principle, morally correct" (Introna 1997 p. 23). Examples of the managerial virtues are rationality (Newell et al. 2001), motivation, effectiveness, and efficiency. But there are also less tangible virtues. The manager is reliable and keeps his calm in the storm. He is a leader but also reassuring and helpful. The fact that few, if any, individuals actually combine all of these characteristics does not diminish their importance as an ideal type. It is justified to call this understanding of management heroic management because the individual manager is depicted as a hero, the savior of the organization. And just like the term heroic has the connotation of good and desirable, the same is true for the term management (Lawler 2004).

Despite the fact that it is probably the predominant view of management, heroic management also runs into problems. One academic approach that is interested in the downsides and weaknesses of heroic management is critical management studies (Alvesson and Deetz 2000). The problems of heroic management can be divided in practical, theoretical, and ethical ones.

The main practical problem is that heroic management often does not work. The heroic approach to project management, for example, does not seem to affect the outcome of projects (Couillard 1996). Managers are caught up in webs of relationships which make it hard for them to establish their heroic leadership, and even if they do,

\footnotetext{
'Oxford English Dictionary, 2004, "Management" (online at http://athens.oed.com/).
} 
there are conflicts with other managers holding similar positions as well as internal conflicts regarding other roles managers may play (Knights and Willmott 1999).

Theoretical problems concern the fundamental reasons why heroic management tends to fail. These include the fact that the very idea of heroic management is a socially constructed category which may be more or less suited to a specific situation, depending on the composition of the group to which management is applied. This means that the acceptability of heroic management is not in the hands of the manager, diminishing his control of success or failure. Another theoretical argument against the concept of heroic management is that it overlooks the fundamental determinants of humans who act as managers. Managers are not the abstract rational homines economici described in parts of the management literature; they are being-in-the-world in a Heideggerian sense (Heidegger 1992; see also Ciborra 2002; Introna 1997). They are incapable of leaving their bodily situatedness, the fact that they are always caught up in situations (Lawler 2004) as well as the ideologies and discursive webs surrounding them (Levy et al. 2003). The myth of rationality, on which heroic management is built, is thus exposed as untenable. Rational decisions in a decision-theoretic model are the rare exception for managers who have to make do in bounded rationality, and for whom emotions are often more important than objective information (Fineman 2001). Managers have to make sense of an uncertain and changing world (Hughes et al. 2002; Thomas 1999).

The myth of rationality, which I assume to be at the base of heroic management and its failure, deserves more attention than I can give it here. It goes back to Max Weber's distinction of different types of rationality, and most importantly to his idea of purposive rationality ( $Z$ weckrationalität). This type of limited rationality is typical for the organization of capitalist economies and thus a central issue of critical research (see Habermas 1984; Stahl 2005). It is closely related to the myth of control, namely that managers can and want to control social action according to their ends. I contend, without being able to argue the point in detail, that the basis of the problems is a limited understanding of rationality, which, if transcended, would overcome the myth of control as well as heroic management.

Another point of critique of the heroic ideal comes from feminist scholars. Adam (2001) shows that the concept of the lone savior/hero is not confined to management but finds its equivalent in engineering as well. She argues that this is problematic because it is a gendered description which gives preference to behaviors that are traditionally associated with men. It thereby gives rise to ethical approaches which emphasize the confrontational nature of ethics and therefore can be blind to more efficient conciliatory solutions. The metaphor of the hero is thus not only misleading but also ethically problematic. This line of argument can lead us to the question of the link between responsibility and heroic management.

\subsection{Heroic and Responsible Management?}

We have now seen that heroic management is per se problematic. Apart from the arguments outline above, there are other issues that the critical management literature so far has not picked up on. The one aspect that I want to develop in this paper is the difficulty of combining heroic and responsible management. Initially, responsible management here stands for the use of management to address and solve ethical and moral issues. These are issues that have to do with good and bad, right and wrong, and 
with the question how we justify such distinctions (for a detailed account of responsible management in IS, see Stahl 2004). Responsible management is thus the desirable approach to issues such as digital divides. Digital divides seem to be a topic where there is a strong initial perception that something is wrong and should be changed. It is not always obvious, however, what exactly is wrong and how it should be changed or by whom. Managing digital divides responsibly would mean identifying the problems, finding solutions, and resolving the issues. While this is generally difficult, I think that there are two reasons why it is fundamentally impossible to use the traditional heroic way of managing for such issues of responsibility: the problem of self-awareness and the problem of conceptual consistency.

\subsubsection{Problem I: Detached Rationality and Objective Reality-The Problem of Self-Awareness}

Responsibility ascriptions are complex social processes that can raise problems for a variety of reasons, which this paper will not be able to cover. There are, however, structural problems of responsible heroic management that cannot be overcome in the traditional top-down objectivist mindset. The attempt to manage digital divides clearly shows this. There are moral issues of distribution and equality of access. There are ethical issues of finding supporting arguments for the solution to moral issues. But there is also the problem that it is not completely clear what the problem is. The issues related to digital divides are not objectively given. Rather, they are based on individual and social experiences and develop over time. They are culturally variable and depend on a number of immeasurable factors. A heroic top-down approach will be unable to identify all of these, not because of a lack of effort, but because they have no objective context-independent reality that would allow describing them in an algorithmic way.

An important aspect of this problem is that management is not a detached entity with a privileged observer position with regard to digital divides but an involved agent that constitutes part of the problem. Managerial or political decisions set the framework for questions of access. National or local questions of divide are directly linked to the institutional environment and also to local management styles. The same can be said for divides within organizations, which will depend to a large extent on managerial decisions. Furthermore, political or management decisions regarding digital divides are necessarily based on preconceived moral ideals and (often implicit) ethical convictions. These will rarely be identical to those of the citizens or employees who are affected. Political leadership and management thus introduce and privilege a certain morality, which in itself will usually constitute an ethical problem.

I should clarify that these problems are not caused by bad leaders or bad management practices. Rather, they are intrinsic in heroic management that takes an objective reality for granted and believes that problems can be addressed from a detached and rational point of view. A resulting fundamental problem is that legitimate concerns of citizens or employees based on their moral or ethical views cannot be accommodated in such an objectivist world view. That means that where concerns are raised, these will typically be considered resistance to change, which leadership must overcome. Since the affected citizens or employees see their objections as justified, management will have to make use of formal powers to overcome the perceived resistance. This will not solve the underlying problem but instead create another moral issue. 


\subsubsection{Problem II: Responsible Use of Responsibility- The Problem of Conceptual Consistency}

The second problem of the attempt to manage responsibly within the mindset of heroic management refers to the concept of responsibility itself. There are three fundamental characteristics of responsibility: openness, affinity to action, and teleology. I have elsewhere developed in more depth the concept of reflective responsibility (Stahl 2004). The basic idea of reflective responsibility is that a normative idea like responsibility should be applicable to itself without contradiction. That means that the use of the concept of responsibility should be a responsible action. Or, to break this down to the main characteristics, an ascription of responsibility should be open, lead to action, and support the intended telos, the aim of responsibility. Reflective use of responsibility should thus determine whether an ascription is indeed viable and whether it can achieve its aims.

Considering this question will require attention to detail in every single case, which is impossible to do in an academic paper. There are, however, a number of issues that can be discussed in general terms. These can be divided according to the main dimensions involved: subject, object, and authority. The subject is the entity that is responsible. In heroic management, this will be a manager. The higher up in the hierarchy, the more responsibility one will expect. This exclusive focus on individual responsibility is problematic, however, because in complex modern organizations, it is usually not trivial to draw a direct line between individuals and certain actions or decisions. This problem is exacerbated when we look at political settings, which dominate digital divides issues. Many decisions are taken by collectives or emerge from the history of the organization without being attributable to a single person. Moreover, individuals do not meet all of the conditions that need to be fulfilled in order for responsibility to be acceptable: freedom, knowledge, and power (Fischer 1999; Goldman 1999). Individuals higher up in the hierarchy will often have more freedom and power, but they lack the local knowledge of pertinent problems. Those individuals who have the local knowledge typically have no power to change things. With regard to digital divides this means that it is not clear who should be held responsible.

The subject is responsible for the object of responsibility. A traditional approach would define the objects at the outset. For digital divides, this might include measures of access for different groups or the availability of technology or education. Even where they were not contentious, such objects would be problematic. The main problem here is what we call side effects. Side effects are those consequences of actions that are caused but not intended. The provision of technology or access can lead to unwanted consequences. Where equality of access should create equality of use and opportunities, it is possible that those who are better educated anyway will profit most. Equaling the digital divide may mean that resources have to be expropriated and redistributed, thus creating new problems of justice. Technology, once provided can be misused, for example for hate speech, promotion of terrorism, or child pornography.

The main problem of the object of ascription is that a top-down objectivist approach is likely to miss a considerable number of the most relevant issues, including most moral questions. Again, this is not the case because managers do a bad job, but because moral problems are context-dependent and emerge from continuous interaction. They are thus 
not completely identifiable from an external observer's position, a position assumed by heroic management.

The main problem with heroic management in this context is that it privileges a particular viewpoint, namely, that of management in the process of establishing and sanctioning responsibility. Most ethical theories are based on the idea that ethical evaluations must be impartial. A heroic and detached approach to responsibility can, by definition, not be impartial because, even when considering other stakeholders' views, it determines outcomes on the basis of management's view of the world.

A traditional approach to responsible management of digital divides thus falls short of the requirements of responsibility with regard to the major dimensions: subject and object. If it cannot identify the right subject, it will miss some of the relevant objects and it will not be based on an acceptable set of norms and thus not produce viable sanctions. To reiterate the point: This is not because managers are bad people or because management does not do its job well. The problems I have discussed are structural and conceptual. They are based on the intrinsic contradiction between a traditional and heroic approach to management and the requirements of responsibility.

\section{REFLECTIVE AND RESPONSIBLE MANAGEMENT: THE SOLUTION?}

So far the paper has argued that there are substantial conceptual problems related to the attempt to responsibly manage the normative problems raised by digital divides. To return to the question in the title of this paper, responsible management of information systems indeed seems to be an oxymoron, at least in so far as management is understood in the traditional top-down scientifically rational way, which I have termed heroic management. What conclusions can we draw from this? The simplest one would be to stop speaking of responsibility and management. However, responsibility is a concept closely linked to management and managers tend to be proud of the fact that they are responsible people. It also allows highlighting ethical issues such as digital divides. The next solution is thus to simply ignore the issues raised in this paper. Heroic management that concentrates on political or organizational imperatives and neglects the wider context can still be promoted. It will have blind spots and not be sensitive to the moral and ethical issues discussed in this paper, but it can be used to further specific ends. Anecdotal evidence suggests that this is the solution frequently chosen. Such an approach has two major disadvantages: an ethical and an organizational one. The ethical disadvantage is that responsibility understood in a top-down strategic manner will fail to pick up on many moral problems raised by digital divides. Furthermore, it does not have the ethical breadth to deal with those it does pick up. It will thus ignore relevant and legitimate concerns or will try to suppress them as unjustified resistance to change.

The political and organizational problem of the approach is its insensitivity to moral and ethical questions, which can lead to problems of implementation. When solutions to problems of digital divides are sought by implementing decisions agreed upon by individual leaders, it is likely that this will lead to resistance because legitimate concerns have been overlooked. The heroic approach can, therefore, backfire. 
The alternative to this unsatisfactory approach would be to understand the concept of management in a different way, in a way that is compatible with the concept of responsibility. This is where we come back to the idea of reflective responsibility introduced earlier. Reflective responsibility is the attempt to realize the ascription of responsibility in such a way as to render it a responsible activity. This means that responsibility is ascribed in such a way that it will be open (in terms of process and outcome), that it will have manifest results, and that it furthers the original intention of the ascription. It goes far beyond the confines of this paper to describe the details of reflective responsibility (for an in-depth discussion, see Stahl 2004). Suffice it to say that reflective responsibility will require participative processes that define all steps and dimensions of responsibility in an interdependent way. That means that an instance of responsibility needs to be defined in terms of subject, object, and norms or sanctions. The subjects need to be chosen so that they can affect the outcomes, adhere to the norms, and react to the sanctions. In terms of digital divides, this will mean that there is no one single ascription of responsibility but rather a web of interlinking responsibilities that will refer to one another. Subjects will most likely include political leaders or individual managers but they will not be confined to these. It is possible for individual citizens to become subjects of responsibility or collectives or whole organizations. This reconceptualization of responsibility subjects may open avenues for paying closer attention to gender issues, for example by underlining the importance of hero helpers or sybils (Adam 2001) as counter-metaphors to the lone hero.

The objects will include the traditional (equality of access, provision of technology, provision of education) but they will go beyond these, covering questions of respect, minority issues, unintended side-effects, and whatever else the affected parties find worthy of ascribing responsibility. The relationship between subject and object will be defined on the basis of acceptable norms, which can be economic ones (profit maximization), but which can also be explicitly ethical (autonomy, freedom, justice) or of a different nature (tradition, local culture).

It should be clear that such a web of responsibility requires a fundamentally different type of interaction between leaders and other stakeholders from the one implied in heroic management. In practice, the process of responsibility ascription will look more like Habermasian discourse (Habermas 1981) or a stakeholder debate in the sense of stakeholder management (Donaldson and Preston 1995). It also embodies the ideal of democracy with autonomous and independent citizens. The main advantage of this reflective approach to responsible management of normative issues of IS is that it allows the identification and consideration of the wide range of moral and ethical issues that are potentially raised by digital divides. It faces neither of the two main problems of heroic management discussed in this paper. Since it is not a one-sided, top-down and powerbased responsibility, leadership does not have the most important place. Leaders are, of course, legitimate stakeholders in the process of ascription and they can argue for their desired objectives. However, they need to take into consideration the viewpoints of other stakeholders. This allows a definition of the problems (objects of responsibility) that overcomes the partial interests of management. The ascription is, therefore, not fraught with the problem of self-awareness. By considering questions of realizabiltiy and desirable outcomes, the process of ascription also addresses the second main objection raised above. The simultaneous definition of subject, object, and authority allows the development of viable ascriptions. Finally, the web of responsibility created 
in this way needs to remain open to revision and thus is not a static construct. It can react to changes by adding or modifying ascriptions.

The critical reader can raise a number of objections to the model of reflective responsibility. The main ones are that it is a hugely complex undertaking, particularly when applied to large processes, and that it does not offer a guarantee of success. These points of critique are valid but can be countered from the point of view of reflective responsibility. It is an intrinsic characteristic of reflective responsibility that it is modest in its goals; that it aims to further the moral objectives of the community of discourse without claiming that it will achieve perfection. The counterargument would thus be that the reflective approach at least offers the possibility of overcoming the shortcomings of heroic responsibility and that such an attempt should be worth the cost, first because it can help overcome organizational problems, and second because it is a morally acceptable way to deal with the other. There are, of course, other counterarguments, which aim at the heart of participatory approaches, which I cannot discuss here (see Kvasny and Truex 2000; Wilson 1997).

There is, however, another reason why it is difficult to accept this approach. The role of the leader in this setting changes drastically. He is no longer the lone and rational hero who brings salvation to the organization. Instead, he becomes an involved member of a community and, at best, a facilitator of discourses. This goes counter to the self-description of many leaders as well as our social perception of them. It requires a wider discourse aimed at redefining management and leadership. Without such a discourse and a change of our understanding of the role of managers, the heroic approach to managing responsibly is likely to prevail despite its oxymoronic nature, which will render it impossible to address the moral and ethical issues of digital divides.

\section{References}

Adam, A. "Heroes or Sibyls? Gender and Engineering Ethics," IEEE Technology and Society Magazine (20:3), 2001, pp. 39-46.

Alvesson, M., and Deetz, S. Doing Critical Management Research, London: Sage Publications, 2000.

Alvesson, M., and Willmott, $\mathrm{H}$. "On the Idea of Emancipation in Management and Organization Studies," Academy of Management Review (17:3), 1992, pp. 432-464.

Baecker, D. Postheroisches Management. Ein Vademecum. Berlin: Merve, 1994.

Bourlakis, C. A., and Bourlakis, M. A. "Logistics, Information Technology and Retail Internationalization: The Formation of International Strategic Retail Networks," in L. A. Joia (ed.), IT-Based Management: Challenges and Solutions, Hershey, PA: Idea Group Publishing, 2003, pp. 257-276.

Castells, M. The Information Age: Economy, Society, and Culture. Volume II: The Power of Identity, Oxford, UK: Blackwell, 1997.

Cecez-Kecmanovic, D. "Doing Critical IS Research: The Question of Methodology," in E. Trauth (ed.), Qualitative Research in IS: Issues and Trends, Hershey, PA: Idea Group Publishing, 2001, pp. 141-162.

Ciborra, C. The Labyriths of Information-Challenging the Wisdom of Systems, Oxford, UK: Oxford University Press, 2002.

Couillard, J, "The Role of Project Risk in Determining Project Management Approach," Project Management Journal (26:4), 1995, pp. 3-15. 
Couldry, N. "Digital Divide or Discursive Design? On the Emerging Ethics of Information Space," Ethics and Information Technology (5:2), 2003, pp. 89-97.

Dewan, S., and Riggins, F J. "The Digital Divide: Current and Future Research Directions," Journal of the Association for Information Systems (6:12), 2005, pp. 298-337.

Donaldson, T., and Preston, L. E. "The Stakeholder Theory of the Corporation: Concepts, Evidence, and Implications," Academy of Management Review (20:1), 1995, pp. 65-91.

Fineman, S. "Fashioning the Environment," Organization (8:1), 2001, pp. 17-31.

Fischer, J. M. "Recent Work on Moral Responsibility," Ethics (110:1), 1999, pp. 93-139.

Goldman, A. I. "Why Citizens Should Vote: A Causal Responsibility Approach," in E. F. Paul, F. D. Miller, and J. Paul (eds.), Responsibility, Cambridge, UK; Cambridge University Press, 2003, pp. 201-217.

Gosling, J., and Mintzberg, H. "The Five Minds of a Manager," Harvard Business Review $(81: 11), 2003$, pp. 54-63.

Habermas, J. Theorie des kommunikativen Handelns-Band I+II. Frankfurt: Suhrkamp Verlag, 1981.

Hacker, K. L., and Mason, S. M. "Ethical Gaps in Studies of the Digital Divide," Ethics and Information Technology (5:2), 2003, pp. $99-115$.

Heidegger, M. Sein und Zeit ( $17^{\text {th }}$ ed.), Tübingen, Germany: Max Niemeyer Verlag, 1993.

Hirschheim, R., and Klein, H. K. "Realizing Emancipatory Principles in Information Systems Development: The Case for ETHICS," MIS Quarterly (18:1), 1994, pp. 83-109.

Hughes, J. A., Rouncefield, M., and Tolmie, P. "The Day-to-Day Work of Standardization: A Sceptical Note on the Reliance on IT in a Retail Bank," in S. Woolgar (ed.), Virtual Society? Technology, Cyberbole, Reality, Oxford: Oxford University Press, 2002, pp. 247-263.

Introna, L. Management, Information and Power: A Narrative of the Involved Manager. London: MacMillan, 1997.

Klein, H. K., and Myers, M. D. "A Set of Principles for Conducting and Evaluating Interpretive Field Studies in Information Systems," MIS Quarterly (23:1), 1999, pp. 67-94.

Knights, D., and Morgan, G "Corporate Strategy, Organizations, and Subjectivity: A Critique," Organization Studies (12:2), 1991, pp. 251-273.

Knights, D., and Willmott, H. Management Lives: Power and Identity in Organizations, London: Sage Publications, 1999.

Kvasny, L. "A Conceptual Framework For Examining Digital Inequality," in R. Ramsower and J. Windsor (eds.), Proceedings of the Eighth Americas Conference on Information Systems, Dallas, TX, 2002, pp. 1798-1805.

Kvasny, L., and Keil, M "The Challenges of Redressing the Digital Divide: A Tale of Two Cities," in L. Applegate, R. D. Galliers, and J. I. DeGross (eds.), Proceedings of the $23^{\text {ru }}$ International Conference on Information Systems, Barcelona, Spain, 2002, pp. 817-828.

Kvasny, L., and Truex, D. "Information Technology and the Cultural Reproduction of Social Order: A Research Program," in R. Baskerville, J. Stage, and J. I. DeGross (eds.), Organizational and Social Perspectives on Information Technology, Boston: Kluwer Academic Publishers, 2000, pp. 277-294.

Lawler, J. "Meaning and Being: Existentialist Concepts in Leadership," International Journal of Management Concepts and Philosophy (1:1), 2004, pp. 61-72.

Levy, D. L., Alvesson, M., and Willmott, H. "Critical Approaches to Strategic Management," in M. Alvesson and H. Willmott (eds.), Studying Management Critically, London: Sage Publications, 2003, pp. 92-110.

McAulay, L., Doherty, N., and Keval, N. "The Stakeholder Dimension in Information Systems Evaluation," Journal of Information Technology (17), 2002, pp. 241-255.

McGrath, K. "Doing Critical Research in Information Systems: A Case of Theory and Practice Not Informing Each Other," Information Systems Journal (15), 2005, pp. 85-101. 
McSorley, K. The Secular Salvation Story of the Digital Divide," Ethics and Information Technology (5:2), 2003, pp. 75-87.

Moss, J. "Power and the Digital Divide," In: Ethics and Information Technology (4:2), 2002, pp. 159-165.

Newell, S., Swan, J., and Kautz, K. "The Role of Funding Bodies in the Creation and Diffusion of Management Fads and Fashions," Organization (8:1), 2001, pp. 97-120.

Ngwenyama, O. K., and Lee, A. S. "Communication Richness in Electronic Mail: Critical Social Theory and the Contextuality of Meaning," MIS Quarterly (21:2), 1997, pp. 145-167.

Norris, P. Digital Divide-Civic Engagement, Information Poverty, and the Internet Worldwide, Cambridge, UK: Cambridge University Press, 2001.

Parayil, G. "The Digital Divide and Increasing Returns: Contradictions of Informational Capitalism," The Information Society (21:1), 2005, pp. 41-51.

Rookby, E. (ed.). Information Technology and Social Justice, Hershey, PA: Idea Group Publishing, 2006.

Schiller, D. Digital Capitatism: Networking the Global Market System, Cambridge, MA: MIT Press, 1999.

Stahl, B. C. "The Obituary as Bricolage: The Mann Gulch Disaster and the Problem of Heroic Rationality," European Journal of Information Systems (14), 2005, pp. 487-491.

Stahl, B. C. Responsible Management of Information Systems, Hershey, PA: Idea Group Publishing, 2004.

Thomas, R. J. "What Machines Can't Do: Politics and Technology in the Industrial Enterprise," in D. MacKenzie and J. Wajcman (eds.), The Social Shaping of Technology (2 ${ }^{\text {nd }}$ ed.), Maidenhead, UK: Open University Press, 1999, pp. 199-221.

UNDP. Human Development Report 1998, United Nations Development Programme, New York: Oxford University Press, 1998.

Varey, R. J., Wood-Harper, T., and Wood, B. "A Theoretical Review of Management and Information Systems Using a Critical Communications Theory," Journal of Information Technology (17), 2002, pp. 229-239.

Walsham, G. "Development, Global Futures and IS Research: A Polemic," paper presented at IS Perspectives and Challenges in the Context of Globalization, IFIP Working Groups 8.2 and 9.4 Joint Conference, Athens Greece, June 15-17, 2003.

Wilson, F. A. "The Truth is Out There: The Search for Emancipatory Principles in Information Systems Design," Information Technology and People (10:3), 1997, pp. 187-204.

\section{About the Author}

Bernd Carsten Stahl is a senior lecturer in the Faculty of Computing Sciences and Engineering and a research associate at the Centre for Computing and Social Responsibility of De Montfort University, Leicester, UK. His interests cover philosophical issues arising from the intersections of business, technology, and information. This includes the ethics of computing and critical approaches to information systems. He is the editor-in-chief of International Journal of Technology and Human Interaction. He can be reached at bstahl@dmu.ac.uk. 